\title{
Current Problems in Extraordinariness Situations with the Impact on the Management of Rail Transport Under the Conditions of Slovak Railways
}

\author{
Juraj Čamaj ${ }^{*}$, Ján Ponický ${ }^{2}$, Lumír Pečený1 ${ }^{1}$ Pavol Meško $^{1}$ and Karel Zeman ${ }^{3}$ \\ ${ }^{1}$ Department of Railway Transport, Faculty of Operation and Economics of Transport and Communications, Univerzitná 8215/1, 01026 \\ Žilina, Slovakia \\ ${ }^{2}$ Železnice Slovenskej republiky, The Regional Directorate Žilina, The Railway Station Dolný Hričov, Slovakia \\ ${ }^{3}$ Institute of Technology and Business in České Budějovice, Faculty of Technology, Department of Informatics and Natural Sciences, \\ Okružní 517/10, 37001 České Budějovice. Czech republic
}

\begin{abstract}
Rail transport is a dynamic and progressive process. It is important that the requirements of individual carriers be meet as efficiently as possible in accordance with the current train schedule. In the case of extraordinariness situations (delay, reconstructions activities, different routing of a train, etc.), which affect the fulfilment of train schedule, are applying so called "operational traffic management according to the applicable internal regulations". In the event of the occurrence of these extraordinary situations, it is necessary to compile a written injunction in order to inform the train drivers about these extraordinary circumstances. The introduction of an electronic injunction system causes the opposite effect in selected situations, such as rapid, accurate, and effective delivering this paper injunction. The article focuses on the current problem of introducing a new information system for the compilation and creation of written injunctions in relation to selected types of injunctions and situations in the railway transport.
\end{abstract}

\section{The Structure of Operational Management in Railway Transport}

Operational transport management on the network of Slovak railways (ŽSR) network is divide into several levels. Within each level of operational management, there is always one responsible manager of ŽSR leading changes (figure 1), which ensures in its assigned area the operational management of railway transport. [1]

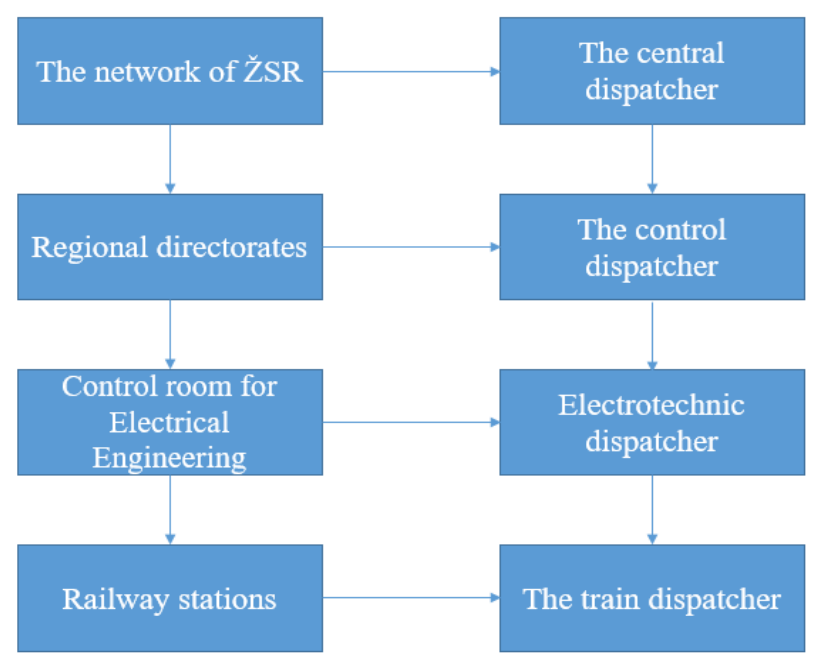

The individual employees of the dispatching apparatus are all subordinate employees of the ŽSR and the transport dispatchers who participate in the strategic and operational management of the railway transport. [2] In the context of operational traffic management, $\mathrm{j}$. in the case of extraordinary situations (delay, reconstructions activities, different routing of a train, etc.), which have an impact on the fulfilment of the train schedules, proceeds in accordance with regulation SR 1003 Operational Management of Transport at Slovak railways.[3]

\subsection{The managers for operation management of the General Directorate level}

The Central dispatcher is the head of change on the entire network of Slovak railways. The central task of the central dispatcher is to manage and coordinate all traffic management activities on the Slovak Railways network in a comprehensive manner [4].

The central dispatcher cooperates with the main dispatcher and the individual dispatchers at the level of the Regional Directorates.

$\mathrm{He}$ coordinates activities with foreign railway administrations, carriers, state administration bodies and the control dispatchers of the Regional Directorates (fig. 2). [5]

Fig. 1. Head of change in individual circuits.

\footnotetext{
* Corresponding author: juraj.camaj@,fpedas.uniza.sk
} 


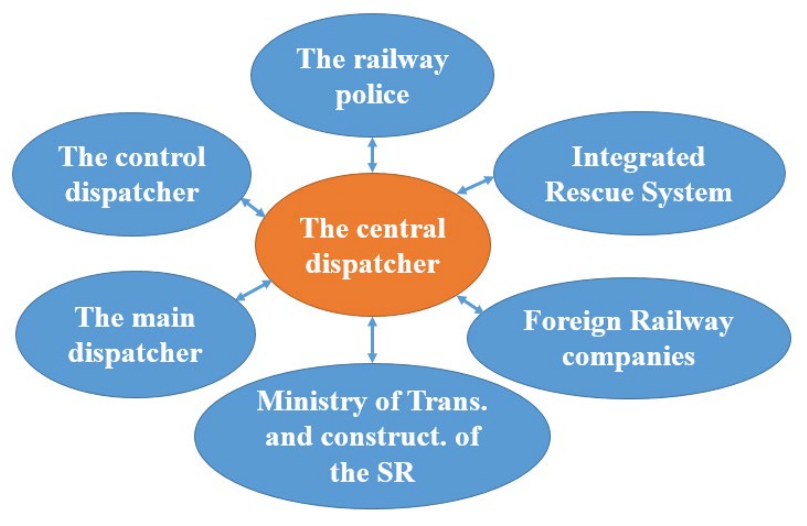

Fig. 2. Links of the central dispatcher to other entities.

The main dispatcher coordinates, in cooperation with the central dispatcher, all activities on the Slovak Railways network (fig. 3). [5]

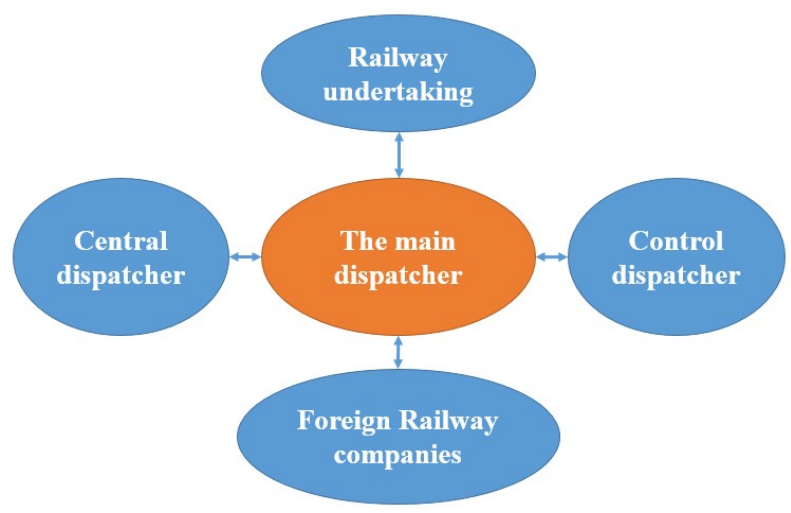

Fig. 3. Links of the main dispatcher to other entities.

\subsection{The Managers for Operation Management on the level of the Regional Directorates}

The Head of Change in the Regional Directorates (Trnava, Žilina, Zvolen and Košice) is the Control dispatcher.[4]

Its main task is coordinating to operationally and comprehensively traffic in its assigned area, in conjunction with other railway administrations and other Regional Directorates. He is responsible for the work of the operating dispatchers in his specified areas, for the optimal solution of the traffic situation (fig. 4). [5]

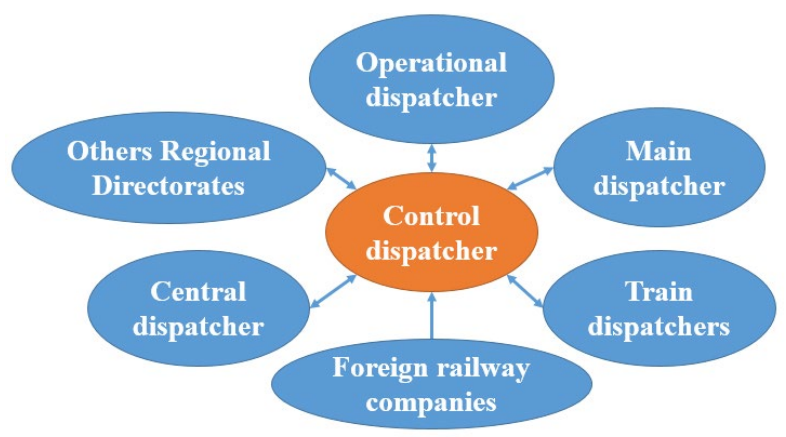

Fig. 4. Links of the control dispatcher to other entities.
The operational dispatcher manages, organizes, coordinates train traffic in its specified areas, and proposes operational measures to address the extraordinariness situations that impact of the train schedule (fig. 5). [5]

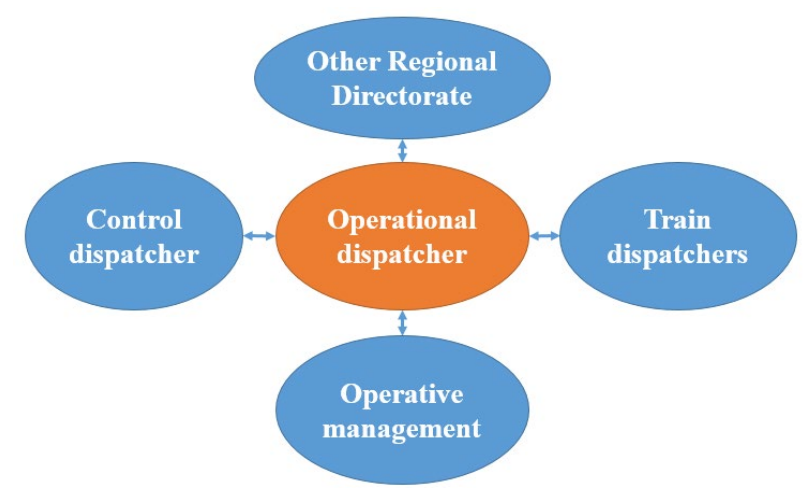

Fig. 5. Links of the operational dispatcher to other entities.

\subsection{The Operating Trains Managers on the level of the Regional Directorate}

The role of operations staffs, i.e. train dispatcher, operating supervisor, station dispatcher, etc. is to implement a shifts plan in the Slovak railways and the allocated disposition sections (fig 6). [5]

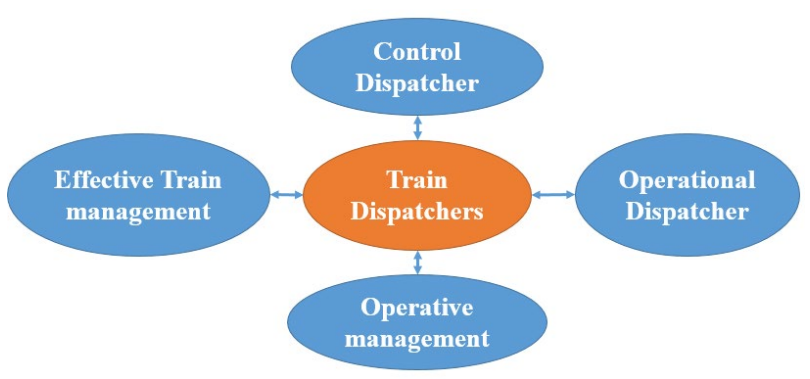

Fig. 6. Links of the train dispatcher to other entities.

\section{Extraordinariness situations in field of the railway transport and the written injunctions}

For all the extraordinariness situations related to train directions, the train driver (and the other train drivers on the active locomotives) must notified by written injunctions. [2]

If the train dispatcher does not receive a report that the train driver was notify by written injunction or himself did not give a written injunction (in case of extraordinariness situations), he must not allow him to go further. [6]

Each written injunction must include the stamp of the station and the signature of the employee who issued the injunction and who takes the injunction. The train driver (or train drivers) who takes the injunction is obliged to read it before acknowledging the receipt (with signature). [7] The written injunction must be clear, concise and legible. 
In the case where the issuing of injunctions is using a computerized technique, the name of the station may be use instead of a stamp, which was place in the same place as a stamp imprint [8]. The font size of the injunction executed on the computing technique must be at least $3 \mathrm{~mm}$.

The train driver must be notifying with the written injunction at the starting or the select station for delivery this injunction or at the last station in front of the place for which the injunction is valid. In the case of regular stopping trains, this is the last station where the train stops regularly.[9]

\subsection{The train driving in the event of a breakdown the interlocking system of level crossing}

The crossing is a level crossing between the road and the railway track. Under Slovak Railways, we divide level crossings to:

- Secured - equipped with crossover interlocking systems,

- Unsecured - without crossover interlocking systems

The next part of paper will be processed measures while riding trains in the event of failure of the level crossing interlocking systems. It means in the conditions while the train not ride through the level crossing with the prescribed manner warn road users that the rail vehicle approaching the crossing or there is another failure.

For monitor the activity and control of the lightsignalling device, a control box is located in the station or track points with indicate the individual states of the level crossings. [10]

In the case of an indication of the fault condition of the level crossing, the train dispatcher is obliged to take the appropriate measures to ensure the train's driving around the fault line - to inform the train driver with the "Injunction for cautious driving - Part A". [3-4] In this section, is for train driver provide all details of the location of the fault level intersection as well as all measures for safe passage of the train through this level crossing. The written Injunction for cautious driving -
Part A is delivered to the train driver at the last station where the train dispatcher is located before the level crossing and where the train stops for the last time. In the injunction, the train dispatcher is obliged to fill in the kilometre position of the level crossing to three decimal places (e.g. 174,052 km) and the names of the stations, or stops etc., between or in which places the level crossing is located. [4]

\section{The electronic application for the written injunctions in Slovak railways}

The application of written injunctions is one of the Modules of the Automated Workstation of the Train Dispatcher. It used to compile the injunctions for the notification of trains and to send them electronically to other workplaces that have the authority to issue the written injunctions. [11] The injunction generated by this application can displayed for a specific track, for a particular train or for unknown trains. It also allows you to create an injunction for handling between stations (HBS). [3]

All necessary data on stations, specified tracks and train timetables are summarizing in the application's root data. The actual application uses the operator to input the data about the trains to notified, i.e., specifies the speed limitation of railway tracks, reconstructions activities, and other extraordinary situations. This information is generally referring to as an instruction. The written injunctions for train notification are generating based on the instructions given (fig. 7). [12]

Creation of injunctions a based on the facts that the operator gradually enters the instructions in the application as they are informing about them in time. At the time when the injunction is needed, the operator enters a command to create one of the types of injunctions (The General injunction, The Injunction for cautious driving - Part A, [4] [13] The Injunction for cautious driving - Part B, The Injunction for handling between stations). The application then selects appropriate instructions and assembles them to one or more injunctions. [9-10]

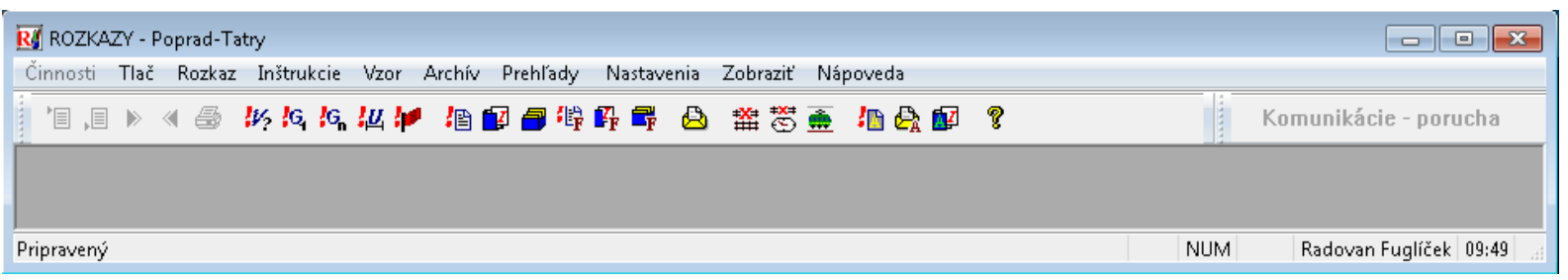

Fig. 7. The main window of Application for the written injunctions.

\subsection{The links between templates, instructions and injunctions in the Application}

Instruction refers to the part of the injunction that applies to a particular section, multiple sections, or the entire route. In order to work with the instructions, you need to create and see a list of instructions. [4]
To create an instruction, you need to fill in all required fields. In total, these fields are 19 (Fig. 8). [12] [13] Their completion is conditional on the data stored in 
the application's root data. Each of the fields is bound to others, and some of them cannot omitted.

The creation of individual instructions is very complex. From the point of view of complex reconstructions of railways, instruction creation and forwarding between stations are acceptable. Likewise, the subsequent creation of written injunctions.

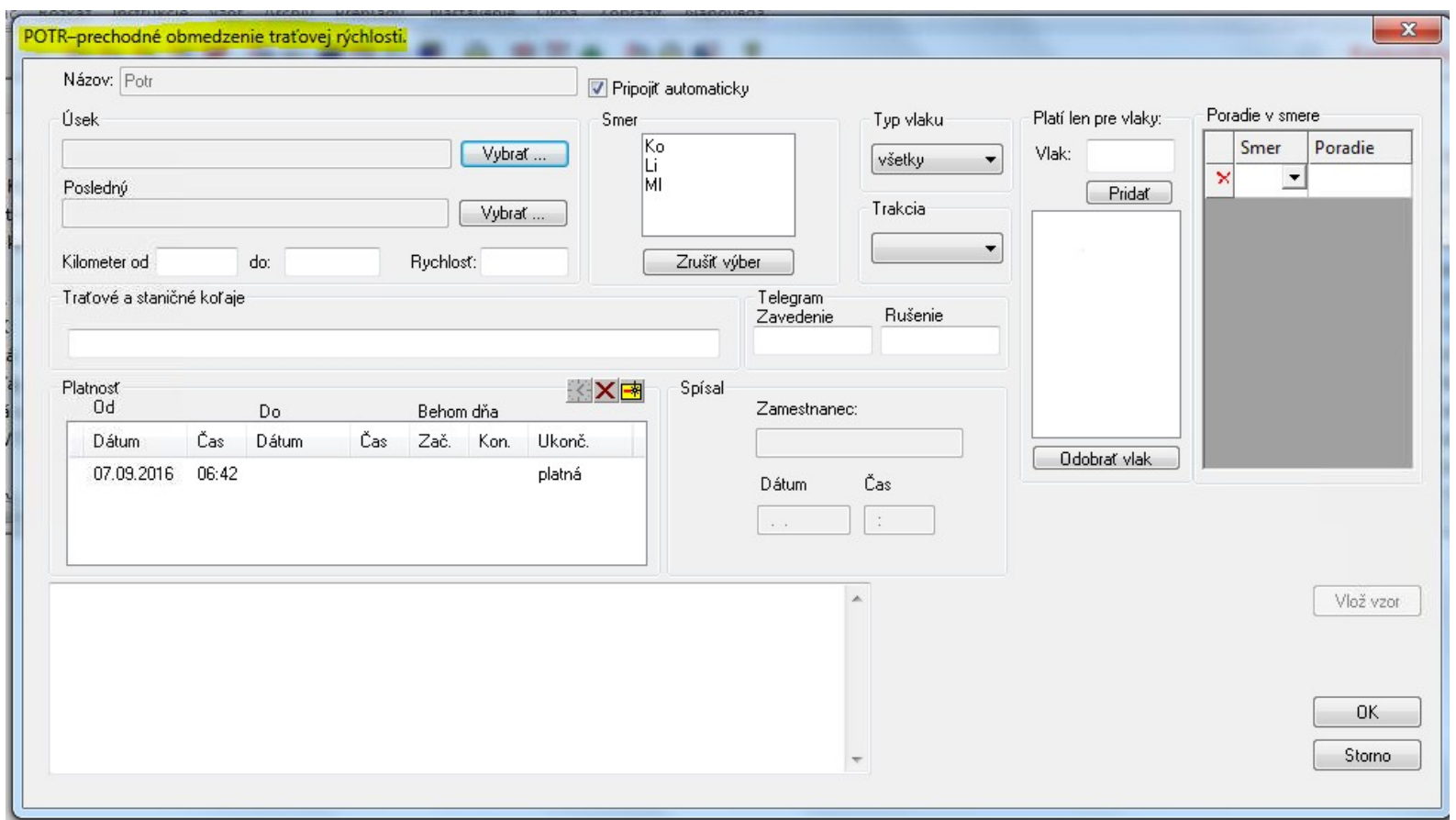

Fig. 8. The main window for creating the instructions in application.

\section{Current problems with the application of injunctions and their possible solution}

In cases where the train dispatchers deal with individual operating failures (level crossings, signal lights, etc.), the compilation process of writing orders from the instructions is very stressful and lengthy. The train dispatcher must inform all competent departments (operating dispatcher, etc.) from his position, manage the other train traffic, and create instructions for a new written injunction. All these tasks carried out in time stress, which caused precisely with a view to minimizing the delays of the affected trains. [14]

However, the users are also available with template's he previously created in the application. [4, 14] The compilation process of the written injunctions is most visible in the case of the Injunction for cautious driving Part A and Part B very long and stressful.

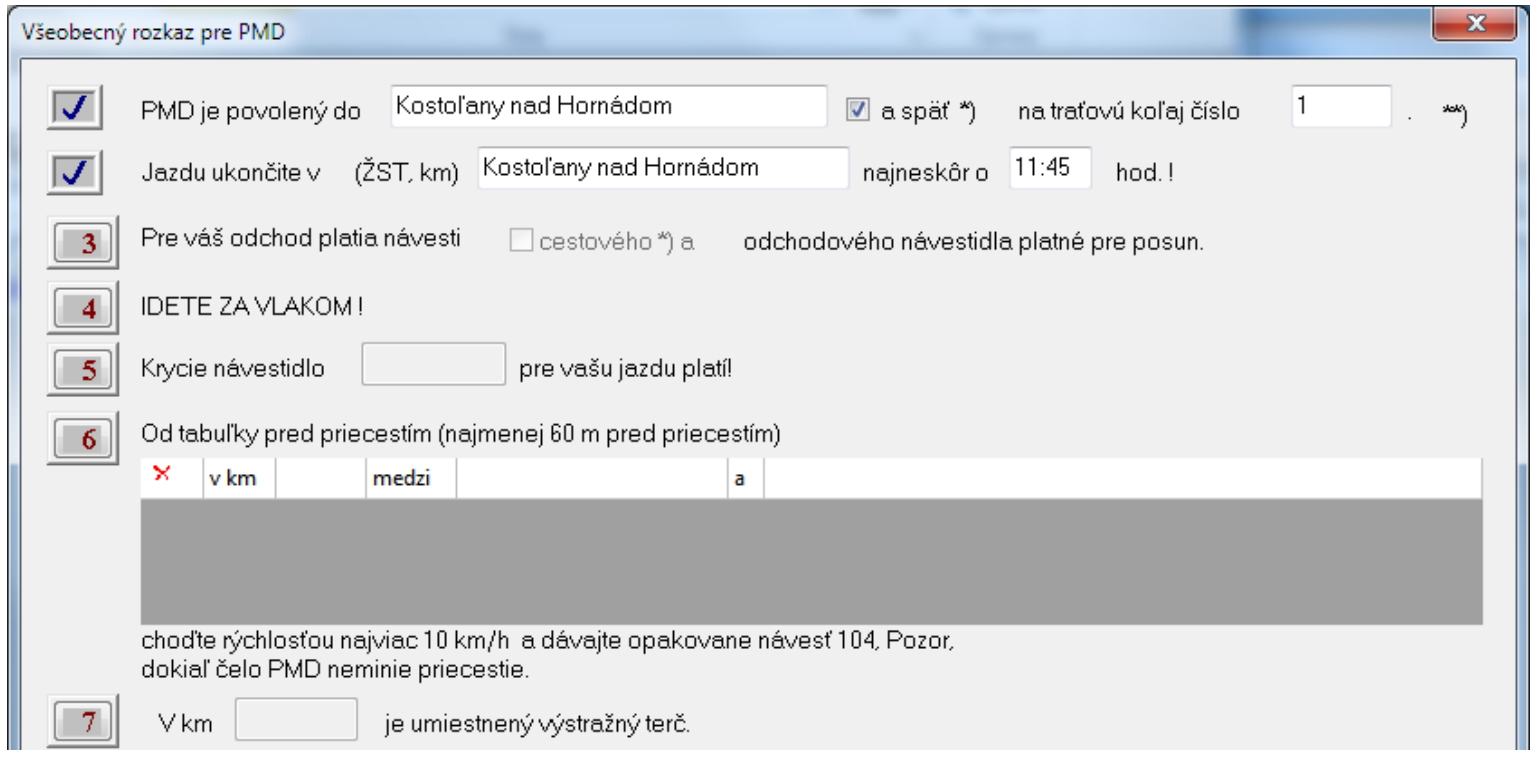

Fig. 9. The main window the injunction for handling between stations 
The solution for the Injunction for cautious driving could be another type of the injunction - The injunction for handling between stations (Figure 9). [12] In this case, the operator completes with double-click to mouse the particulars applicable to the handling between stations.

The solution is the possibility that the operator should, in the case of the Injunction for cautious driving, the possibility of the template of this injunction. [7]

In the above-mentioned template, a simple double click would complement the specific kilometres positions of the level crossings. Based on the inserting the kilometres positions of the level crossing, shall be inserted to the injunction obligatory information automatically (from the root data of the application). [2] The compilation process of the Injunction for cautious driving would be very simple, user-friendly and minimize the stress factor too in its compilation technique. [14]

\section{Conclusion}

In the case of extraordinariness situations (delay, reconstructions activities, different routing of a train, etc.), which affect the fulfilment of train schedule, are applying so called "operational traffic management according to the applicable internal regulations". In the event of the occurrence of these extraordinary situations, it is necessary to compile a written injunction in order to inform the train drivers about these extraordinary circumstances. The compilation process of the written injunction is very complex and also very stressful and lengthy. The compilation process of the written injunctions is most visible in the case of the Injunction for cautious driving - Part A and Part B.

The solution for this Injunction for cautious driving could be another type of the injunction - The injunction for handling between stations. With all knowledge's from other written injunctions, the compilation process of the Injunction for cautious driving would be very simple, user-friendly and minimize the stress factor too in its compilation technique.
This research was financially supported by the project VEGA No. 1/0019/17 Evaluation of regional rail transport in the context of the region's economic potential focusing on the efficient use of public resources and social costs of transport.

\section{References}

1. R. Kampf, S. Lorincova, M. Hitka, O. Stopka. Sustainability, 9. (2017) DOI: 10.3390/su9091561.

2. E. Nedeliaková, J. Sekulová, I. Nedeliak. Transport Means - Proceedings of the International Conference. 236-239. (2015)

3. ŽSR Regulation Z1 - Railway Transport Policy. 523 pages. (2011).

4. O. Stopka, R. Kampf. Transport, 33, 280-290. (2018) DOI: $10.3846 / 16484142.2016 .1174882$.

5. ŽSR Regulation SR 1003 - Operational Traffic Management at the ŽSR. 27 pp. (2011)

6. B. Abramović, E. Nedeliaková, M. Panák, D. Šipuš. Proceedings of. 7th International Scientific Conference on Business Logistics in Modern Management. 15-28. (2017)

7. J. Gašparík; B. Abramović, M. Halás Promet Traffic \& Transportation. 27, 4. 283-290. (2015)

8. G. Fedorko, V. Molnár, J. Strohmandl et al. Transport Means 2015 - Proceedings of the International Conference. 466-+ (2015)

9. L. Černá, A. Dolinayová, J. Daniš. Proceedings of the 20th International Scientific Conference Transport Means 2016. 414-419. (2016).

10. V. Lupták, J. Gašparík, M. Chovancová. MATEC Web of Conferences. 134. Article Number: 00033. (2017).

11. A. Dolinayová, J. Kanis, M. Loch, Procedia Engineering, 134. 187-195. (2016).

12. B. Abramović, J. Gašparík, Jozef, V. Zitrický. Tehnički Vjesnik. 25, 4. 1190-1195. (2018)

13. V. Zitrický, L. Černá, B.Abramović. Procedia Engineering. 192. 994-999. (2017)

14.ŽSR User manuals - Applications of Electronic Injunctions. Version 3.95. 52. (2017)

\footnotetext{
Corresponding author: juraj.camaj@,fpedas.uniza.sk
} 